\title{
del Nido cardioplegia: Ready for prime time in adult cardiac surgery?
}

\author{
Niv Ad, MD
}

\section{See related article on pages 626-36.}

Adequate myocardial protection during cardiac surgery is essential to successful clinical outcomes. ${ }^{1}$ Since their introduction in the 1970s, hyperkalemic cardioplegic solutions have become the gold standard for myocardial preservation. ${ }^{2}$ Electromechanical arrest can be achieved through depolarization of the extracellular membrane potential, which decreases the resting potential of ventricular myocytes via the delivery of a hypothermic potassium chloride-enriched solution directly to the coronary circulation. After an initial dose, electromechanical quiescence is achieved, and intermittent doses (every 20-30 minutes) are then required to sustain arrest and provide washout of metabolic inhibitors. The timing of these delivery doses is critical to avoid myocardial dysfunction.

Despite a multitude of commercially available cardioplegic solutions, no clear consensus has been reached on the optimal composition or technique for using them..$^{2-4}$ The use of blood-based solutions has been associated with significant reductions in perioperative cardiac enzymes and reperfusion mediators. However, such studies have failed to demonstrate differences in clinical outcomes. Heterogeneity in delivery temperature, dosing frequency, and substrate composition makes it difficult to evaluate these solutions.

A novel formula for inducing cardioplegia was introduced in congenital heart surgery in $1995 .{ }^{5,6}$ Led by Pedro del Nido, MD, researchers from the University of Pittsburgh patented this formula as a single dose of a modified depolarizing solution. Commonly referred to as "del Nido solution," this blood and crystalloid mixed formula (1:4) allows for a longer duration of safe myocardial ischemic arrest. ${ }^{6}$ This unique formula reduces energy consumption, blocks calcium flux into the intracellular environment, scavenges hydrogen ions, preserves high-energy phosphates, and promotes

\footnotetext{
From the Department of Cardiac Surgery, Inova Heart and Vascular Institute, Falls Church, Va.

Disclosures: Author has nothing to disclose with regard to commercial support. Received for publication Nov 11, 2014; accepted for publication Nov 13, 2014. Address for reprints: Niv Ad, MD, Department of Cardiac Surgery, Cardiac Surgery Research, Inova Heart and Vascular Institute, 3300 Gallows Rd, Suite 3100, Falls Church, VA 22042 (E-mail: Niv.Ad@Inova.org).

J Thorac Cardiovasc Surg 2015;149:637-8 0022-5223/\$36.00

Copyright (c) 2015 Published by Elsevier Inc. on behalf of The American Association for Thoracic Surgery

http://dx.doi.org/10.1016/j.jtcvs.2014.11.021
}

anaerobic glycolysis. ${ }^{7,8}$ Although del Nido solution still contains potassium chloride as the main arresting agent, it includes other additives, such as magnesium sulfate, mannitol, sodium bicarbonate, and lidocaine. Both magnesium sulfate and lidocaine contribute to a safe, prolonged arrest period by blocking calcium and sodium membrane channels, respectively. These properties not only maintain intracellular $\mathrm{pH}$ levels, but also provide more than 90 minutes of safe myocardial ischemia. ${ }^{6,7}$ These observed benefits have made the use of del Nido solution a standard of care in many pediatric cardiac surgical programs. ${ }^{9}$

Stephanie L. Mick, MD, and her colleagues ${ }^{10}$ from the Cleveland Clinic present the outcomes they achieved with del Nido cardioplegia and compare them with those of Buckberg blood cardioplegia in adult patients undergoing isolated valve surgery. In this well-executed study, the authors performed a propensity-matched analysis and concluded that del Nido solution is safe for use in adult primary isolated aortic or mitral valve surgeries. In addition, they pointed out potential advantages of del Nido cardioplegia, including a lower likelihood of surgical interruption, fewer perturbations in intraoperative blood glucose levels, easier postoperative glycemic control, reduced surgical times with certain surgical approaches, and lower costs. The authors appropriately state that caution is still warranted in adopting this form of cardioplegia and that further study is required to establish its indications.

Given that the current method of myocardial preservation with blood cardioplegia is excellent, and that low cardiac output associated with inadequate myocardial protection is an extremely uncommon scenario, we might ask why we should change the way we protect the myocardium during open heart surgery. To answer this question, we need to focus on 2 main issues: (1) the quality and consistency of myocardial preservation and (2) the technical aspects of the delivery of cardioplegic solution.

Widely tested experimental models and extensive clinical experience with the 2 types of solutions have demonstrated that both result in excellent myocardial preservation. Until recently, however, del Nido solution was widely used only in patients with congenital anomalies; the transition to the adult population with valvular heart disease has occurred only recently, driven mainly by individual surgeons. No prospective randomized study has compared the 2 solutions in terms of patient outcomes, efficacy, and safety. Several retrospective studies comparing the 2 myocardial preservation methods have 
demonstrated that del Nido solution is probably safe to use in adults with valvular heart disease. ${ }^{10}$ However, because no real comparisons exist, cautious and appropriate selection criteria should be used.

It is clear that del Nido solution has immediate technical advantages compared with blood cardioplegia, especially in the increasing number of minimally invasive valve cases. The solution allows for longer redosing intervals while providing equivalent myocardial protection. ${ }^{6}$ Therefore, a single antegrade application should be enough in the vast majority of valve cases. In addition, use of del Nido solution may be associated with cost savings, as the need to use relatively expensive retrograde perfusion catheters for minimally invasive cases will be eliminated. Another potential benefit is the shortening of minimally invasive procedures via avoidance of cardioplegic redosing.

The study by Mick and colleagues ${ }^{10}$ is an important one. The authors were very careful in their conclusions not to ascribe causality to their results. The importance of the study's limitations lies in their ability to guide us to the appropriate next steps before del Nido solution becomes more widely used as the preferred myocardial protection method in adult patients with valvular heart disease. Basic research in adult heart models, as well as well-designed, prospective, randomized studies, are required to capture data on multiple preoperative variables, intraoperative changes and techniques, and postoperative care. Although measuring myocardial enzyme levels as a surrogate for myocardial preservation is important, this cannot serve as the sole reliable indicator; other parameters, including cardiac output, myocardial performance by echocardiography, and perioperative outcome, should be included.

\section{References}

1. Follette DM, Mulder DG, Maloney JV, Buckberg GD. Advantages of blood cardioplegia over continuous coronary perfusion or intermittent ischemia. Experimental and clinical study. J Thorac Cardiovasc Surg. 1978; 76:604-19.

2. Ovrum E, Tangen G, Tollofsrud S, Oystese R, Ringdal ML, Istad R. Cold blood versus cold crystalloid cardioplegia: a prospective randomized study of 345 aortic valve patients. Eur J Cardiothorac Surg. 2010;38:745-9.

3. Fallouh HB, Chambers DJ. Is blood versus crystalloid cardioplegia relevant? Significantly improved protection may require new cardioplegic concepts! Interact Cardiovasc Thorac Surg. 2008;7:1162-3.

4. Sá MP, Rueda FG, Ferraz PE, Chalegre ST, Vasconcelos FP, Lima RC. Is there any difference between blood and crystalloid cardioplegia for myocardial protection during cardiac surgery? A meta-analysis of 5576 patients from 36 randomized trials. Perfusion. 2012;27:535-46.

5. Charette K, Gerrah R, Quaegebeur J, Chen J, Riley D, Mongero L, et al. Single dose myocardial protection technique utilizing del Nido cardioplegia solution during congenital heart surgery procedures. Perfusion. 2012;27:98-103.

6. Matte GS, del Nido PJ. History and use of del Nido cardioplegia solution at Boston Children's Hospital. J Extra Corpor Technol. 2012;44:98-103.

7. O'Blenes SB, Friesen CH, Ali A, Howlett S. Protecting the aged heart during cardiac surgery: the potential benefits of del Nido cardioplegia. J Thorac Cardiovasc Surg. 2011;141:762-70.

8. Edelman JJ, Seco M, Dunne B, Matzelle SJ, Murphy M, Joshi P, et al. Custodiol for myocardial protection and preservation: a systematic review. Ann Cardiothorac Surg. 2013;2:717-28.

9. Harvey B, Shann KG, Fitzgerald D, Mejak B, Likosky DS, Puis L, et al; American Society of ExtraCorporeal Technology's International Consortium for Evidence-Based Perfusion and Pediatric Perfusion Committee. International pediatric perfusion practice: 2011 survey results. J Extra Corpor Technol. 2012;44: 186-93.

10. Mick SL, Robich MP, Houghtaling PL, Gillinov AM, Soltesz EG, Johnston DR, et al. del Nido versus Buckberg cardioplegia in adult isolated valve surgery. $J$ Thorac Cardiovasc Surg. 2015;149:626-36.e5. 